\title{
The development and initial validation of the work convictions questionnaire (WCQ) to measure approaches to ethical decision making in the workplace: Part 2
}

Estelle Boshoff, Martina Kotzé \& Petrus Nel

\begin{abstract}
Researchers have indicated that the individual's ethical decision-making approach influences the manner in which ethical problems are managed and decisions are made. It became apparent from the literature that there is a need for the development of a reliable and valid work ethics
\end{abstract}

questionnaire that determines individuals' ethical decision-making approaches. A work ethics questionnaire, the Work Convictions Questionnaire (WCQ), based on six main approaches that influence ethical decision making, was developed and administered to a sample of 524 respondents. Both exploratory factor analysis and confirmatory factor analysis

\section{Estelle Boshoff}

Faculty of Economic and Management Sciences

Department of Industrial Psychology

University of the Free State

Nelson Mandela Drive

Bloemfontein

9300

South Africa

T: +27514013820

E: boshoffe@ufs.ac.za

\section{Tina Kotzé}

Faculty of Economic and Management Sciences

UFS Business School

University of the Free State

Nelson Mandela Drive

Bloemfontein

9300

South Africa

$T:+27514017304$

E: kotzem@ufs.ac.za

\section{Petrus Nel}

Faculty of Economic and Management Sciences

Department of Industrial Psychology

University of the Free State

Nelson Mandela Drive

Bloemfontein

9300

South Africa

T: +27514013823

E: nelp1@ufs.ac.za
Estelle Boshoff holds a PhD from the University of the Free State (UFS). As part of her PhD she developed a work ethics questionnaire which determines individuals' ethical decision-making approaches as well as their level of ethical behaviour. She is a registered Industrial Psychologist and is employed by the UFS as a lecturer. She teaches research methodology and is coordinator of the honours programme. Her focus areas are ethics, psychometric assessment and research methodology.

Tina Kotze is a NRF-rated researcher at the UFS Business School and the Head of Department of Industrial Psychology at the University of the Free State. She is the author and co-author of various publications in national and international academic journals and has delivered various papers at international conferences, mostly in the field of psychometric assessment and organisation psychology, i.e. quality of work life, disability in the work place, emotional intelligence and leadership.

Petrus Nel obtained his PhD, specialising in industrial psychology, from Stellenbosch University. His areas of expertise, as well as lecturing responsibilities, are research methodology and statistics. In addition to lecturing, he also supervises postgraduate students (specifically masters and $P h D)$. As a registered industrial psychologist he regularly evaluates the psychometric properties of questionnaires in terms of reliability and validity. He is currently investigating the usefulness of item response theory and Bayesian analysis in survey research. 
were used to evaluate the psychometric properties of the WCQ. Two competing conceptualisations of the WCQ (one factor and six factors) were evaluated. From the statistical analyses, the six-factor structure exhibited an acceptable fit and high reliability. It can therefore be concluded that the WCQ provides a reliable and valid measure for the six approaches to ethical decision making.

Keywords: ethical decision making in the workplace; work ethics questionnaire; Work Convictions Questionnaire (WCQ); measurement of ethical decision-making approaches

\section{INTRODUCTION}

This article forms part of the reporting of a research project relating to the conceptualisation and measurement of approaches that influence ethical decision making in the work context. The objectives of the research project were, firstly, to investigate, by means of a literature review, the predominant ethical issues that organisations face, and, secondly, the various decision-making approaches that may influence ethical decision making in the work context. In the results of this research, which have been published previously in the African Journal of Business Ethics (Boshoff \& Kotzé, 2011), six main approaches, together with certain corresponding sub-approaches were identified and integrated within a holistic framework of ethical decision making. A further objective of the study was to develop a valid and reliable measurement instrument based on this holistic framework, in order to enable researchers and managers to measure the dominant ethical decision-making approaches in the work context, at both organisational and individual levels. This article reports on the development of this instrument, as well as the measurement properties thereof, in order to determine how accurately the questionnaire measures these proposed six ethical decision-making approaches. This measuring instrument is of a descriptive nature, as it does not measure how 'wrong' or 'right' the specific approach is within the context of work, but purely which approaches are mostly being utilised within the organisation. A subsequent objective of the study was the development of a measuring instrument able to measure the level of ethical behaviour within an organisation, based on the approaches used in a specific situation within the work context. The results of the research related to the latter objective will be reported in a future article.

Abriefoverview of themeasurementinstruments currently available to measure ethical decisionmaking approaches, the rationale for the development of a new measurement instrument, as well as a description of the development of the Work Convictions Questionnaire (WCQ), is provided below. A discussion of the research design, results, conclusion, and recommendations follows.

\section{MEASUREMENT OF ETHICAL DECISION-MAKING APPROACHES}

Individuals' ethical decision-making approaches influence the manner in which ethical problems are managed on a daily basis and behavioural decisions are made within organisations. Ethical decision making includes analysing information and using criteria, either subjective or objective, to compare possible alternatives. Eventually, the choice made by the individual will be based on the individual's ethical decisionmaking approach. Therefore, it is imperative for organisations to be aware of the ethical approaches that are followed by employees, especially those of key decision makers.

From the literature, it is evident that the role of various ethical approaches in managerial decision making has been empirically investigated (Kujala, Lamsa \& Penttila, 2011). An overview of the literature revealed the three most prominent questionnaires used during research on ethical decision-making approaches, including Reidenbach and Robin's Multidimensional Ethics Scale (MES) (Kujala 
et al., 2011), Neumann and Reichel's Attitudes Towards Business Ethics Questionnaire (ATBEQ) (Price \& Van der Walt, 2013), and Forsyth's Ethics Position Questionnaire (EPQ) (MacNab, Malloy, Hadjistavropoulos, Sevigny, McCarthy, Murakami, Paholpak, Natarajan \& Liu, 2011).

One of the most frequently used measures in the field of ethical decision-making approaches is the Multidimensional Ethics Scale (MES), originally developed by Reidenbach and Robin in 1988, and further refined in 1990. The purpose of this scale was to explore the ethical evaluative criteria that individuals use when making moral decisions (Kujala et al., 2011). This scale is based on the assumption that individuals use more than one rationale in making ethical judgments, and that the importance of those rationales is a function of the problem situation faced by the individual (Kujala \& Pietiläinen, 2007). In the original development of the scale (MES-30), five ethical approaches, namely justice, relativism, deontology, utilitarianism, and egoism were measured using 30 items. By means of exploratory factor analysis, Reidenbach and Robin also developed an eight-item short form scale (MES-8) that measures three ethical decision-making approaches, namely moral equity, relativism, and contractualism (McMahon \& Harvey, 2007). The factor structures of both the MES- 8 and the original 30-item pool were examined by McMahon and Harvey (2007), in order to verify the dimensionality thereof. Results of confirmatory and exploratory factor analyses failed to support conclusively that either of the two versions of the instrument provides a clearly multidimensional assessment of ethical perceptions. Both instruments were, instead, dominated by a general factor measuring general ethical perceptions. In this regard, McMahon and Harvey (2007) indicated that numerous studies examined the psychometric properties of the MES-8, with some confirming the threefactor structure, while others indicated a twofactor structure, and yet others a one-factor structure. Furthermore, McMahon and Harvey
(2007) raised the concern that, during the development of the MES, a range of scenarios were used to measure ethical judgements. Yet, only a few of these scenarios were examined in order to determine the psychometric properties of the questionnaire. Also, the factor structure was examined using a separate factor analysis for each scenario, instead of focusing on variability across scenarios.

In 1980, the Ethics Position Questionnaire (EPQ) was developed by Forsyth (n.d.), to measure personal moral philosophy along two dimensions: relativism and idealism. According to Forsyth (n.d.; Davis, Andersen \& Curtis, 2001), those who score high on the idealism subscale reflect a fundamental concern for the consequences of their actions. Said individuals seek to avoid harm, by assuming that good consequences can, with the proper action, always be obtained. Those who receive high scores on the relativism subscale tend to espouse a personal moral philosophy based on the rejection of moral universals (Forsyth, n.d.). A critical analysis of this questionnaire (Davis et al., 2001), by means of construct validity and confirmatory factor analysis with independent samples, indicated the existence of three factors - idealism, relativism, and veracity, which challenges the assertion of a stable twofactor structure. Confirmatory factor analysis suggested that the Veracity dimension is a unique factor, while the discriminant validity of the Veracity Scale was supported by factor loadings. Furthermore, the internal consistency reliability of this scale was reasonably high. Additional analyses examined the relationship between the EPQ factors (idealism and relativism) and moral judgments, indicating a stronger effect of idealism compared to that of relativism. Therefore, it appears that idealism provides a stronger impact on moral judgement (Davis et al., 2001). In light of the aforementioned discussion, Davis et al. (2001) questioned the utility of the EPQ, and recommended more theoretical development and psychometric testing of the EPQ. 
In 1987, the Attitudes Towards Business Ethics Questionnaire (ATBEQ) was developed by Neumann and Reichel (Preble \& Reichel, 1988; Price \& Van der Walt, 2013), in order to measure attitudes towards business ethics. The ATBEQ is based on the business theories of social Darwinism, Machiavellianism, objectivism, and ethical relativism (Preble \& Reichel, 1988; Price $\&$ Van der Walt, 2013). Even though each of the 30 questions directly relates to one of these theories, the actual mapping was not provided (Price \& Van der Walt, 2013). The instrument has been used in various empirical studies relating to attitudes toward business ethics (Moore \& Radloff, 1996; Price \& Van der Walt, 2013; Sims \& Gegez, 2004), yet, the psychometric properties of the questionnaire have not been confirmed, despite recommendations to refine the instrument (Moore \& Radloff, 1996; Price \& Van der Walt, 2013; Small, 1992). In a study by Price and Van der Walt (2013), the results of a principal component did not reflect the ethical philosophies around which the questionnaire was originally built. Instead, the results rendered 11 uncorrelated factors that showed a clear ability to describe the attitudes. Moore and Radloff (1996) further indicated that, although this questionnaire has the potential to measure differences in ethical business attitudes, further refinement is necessary regarding construct validity, design, and scoring, in order for it to become a practically reliable and valid measuring instrument.

From the above, it seems that the measurement of ethical decision-making approaches may be problematic. The different approaches to measuring ethical decision making across studies have led to inconsistencies relating to the nature of approaches to ethical decision making. Additionally, the psychometric properties of some of these instruments are either questionable or not available.

In light of the above, the need arose for a recent, valid, and reliable measuring instrument focusing on the most prominent ethical decision-making approaches as identified in the literature. This study helps to fill this gap by means of the development of such a measurement instrument, and by determining the reliability and validity thereof.

\section{Aim of the study}

The aim of this study was, firstly, to develop a valid and reliable measurement instrument based on the six ethical decision-making approaches identified in Boshoff and Kotzé (2011), in order to be able to measure the approaches most utilised within the work context at both organisational and individual levels. Secondly, the aim was to evaluate the measurement properties by means of a measurement model/ framework and estimates of reliability, in order to determine how accurately the questionnaire measures these proposed six ethical decisionmaking approaches.

\section{DEVELOPMENT OF THE WORK CONVICTIONS QUESTIONNAIRE (WCQ)}

The development of the Work Convictions Questionnaire (WCQ) was based on the holistic framework of approaches that influence ethical decision making. This framework, including a discussion of the six ethical decision-making approaches, was discussed thoroughly by Boshoff and Kotzé (2011). In naming the questionnaire, the word ethics was replaced with convictions, in order to limit the possibility of socially desirable responses.

Figure 1 presents the proposed holistic framework of ethical decision making, which integrates the six main approaches regarding ethical decision making (Boshoff \& Kotzé, 2011). A short summary of the six approaches for which items were developed for purposes of the questionnaire will follow. 


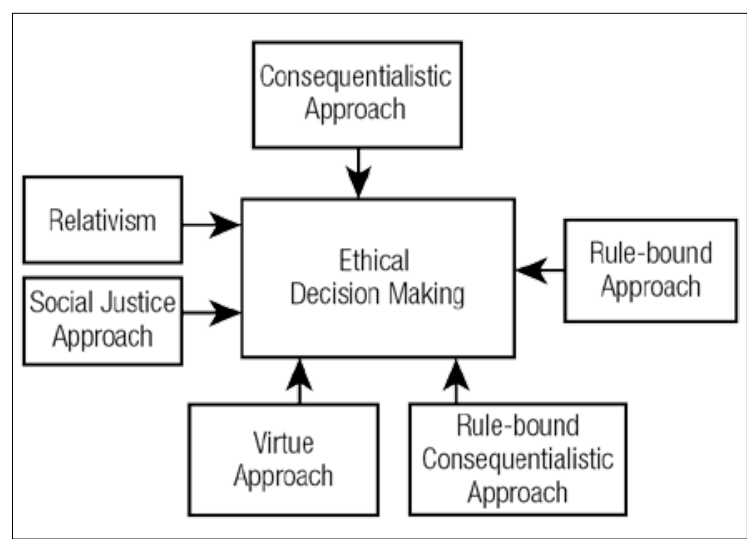

Figure 1: A holistic framework of approaches that influence ethical decision making

\section{The rule-bound approach}

This approach rests on the premise that whether an action or decision is right or wrong, acceptable or unacceptable, depends on whether or not it complies with an accepted moral rule or universal principle (Boshoff, 2009; Esterhuyse, 1991; Malloy \& Zakus, 1995; Rae, 1995). A variety of interpretations of whether an action or decision is right or wrong, acceptable or not, exists within this approach. This includes ethical rationalism, the principle of prohibition, contractualism, and moral and legal rights. In the workplace, employees and employers are confronted with ethical issues pertaining to the rule-bound approach. Various examples of how the rule-bound approach applies within the work context can be distinguished. These examples include the moral obligation of organisations to deliver safe products (Trevino \& Nelson, 2007), as well as to adhere to policies and rules that protect the privacy and confidentiality of clients (Ashley, Powers \& Schunter, 2002; Trevino \& Nelson, 2007), which guide recruitment and selection processes (Swanepoel, Erasmus, Van Wyk \& Schenk, 2003), remuneration (Trevino \& Nelson, 2007), performance management (Malan \& Smit, 2001), and the health and safety of employees (Trevino \& Nelson, 2007). Employees also have a responsibility to adhere to the policies and rules of the organisation regarding whistle-blowing (Desjardins, 2006), fraud, theft, and bribery (Malan \& Smit, 2001; James, 2002; Trevino \& Nelson, 2007).

\section{The consequentialistic approach}

The consequentialistic approach focuses on the consequences of an action or decision, in order to determine the moral quality thereof. Consequentialism therefore rests on the premise that no action or decision is inherently good or bad, acceptable or unacceptable. Only the consequences of the action or decision will determine the acceptability thereof (Boshoff \& Kotzé, 2011; Esterhuyse, 1991; Garofalo, 2003; Malloy \& Zakus, 1995; Trevino \& Nelson, 2007). Within the context of decision making in organisations, an example is providing false and misleading information regarding the possible negative effects of a product, consequently putting the safety and health of customers at risk (Boshoff \& Kotzé, 2011; McCall, 2006; Malan \& Smit, 2001;). Another is business decisions and activities that may result in environmental problems (Boshoff \& Kotzé, 2011; Gibson, 2007). The actions of employees may also result in negative consequences for the organisation. For instance, employees who are unproductive may cost organisations a great deal, and may have a negative effect on the survival of an organisation within a highly competitive global market (Boshoff \& Kotzé, 2011; Malan \& Smit, 2001).

\section{The rule-bound consequentialistic approach}

According to the rule-bound consequentialistic approach, the acceptability of an action or decision is determined by whether it complies with a rule, while the acceptability of the rule depends on the consequences resulting from the application thereof (Boshoff, 2009; Esterhuyse, 1991; Malloy \& Zakus, 1995). Since the moral status and applicability of the rule are determined by the consequences thereof, the possibility that random exceptions can be made is not excluded. Within the workplace, employees and employers are confronted with ethical issues on a daily basis, where decisions cannot merely be guided by rules, norms, or policies on the one hand, or merely by 
judgment of the consequences of said decisions, on the other. In such cases, it is essential for the individual to weigh rules and consequences against one another, and to make a decision within the context of that specific issue.

\section{The virtue approach}

The rule-bound approach, the consequentialistic approach, and the rule-bound consequentialistic approach can be classified as action-orientated ethical approaches. In contrast, the virtue approach focuses, not on the action itself, but on the character of the person conducting the action. According to Aristotle (1972; Garofalo, 2003), only those with a 'good' character are able to do good, and the development of such a character is dependent on the development of virtues (Aristotle, 1977; Rossouw \& Van Vuuren, 2004; Rossouw, Prozesky, Van Heerden \& Van Zyl, 2006). From an organisational perspective, it is of critical importance that employers/management and employees make decisions from a virtue-based approach, and then direct their behaviour accordingly. Some of the virtues that stand out in the work context are those of honesty, integrity, loyalty, and reliability (Boshoff, 2009; Desjardins \& McCall, 1996; Malan \& Smit, 2001). Dishonest behaviour may include bribery, corruption, and fraud (Gordon \& Miyake, 2001; Malan \& Smit, 2001), theft (Gross-Schaefer, Trigilio, Negus \& Ro, 2000; Trevino \& Nelson, 2007), as well as unproductivity (Malan \& Smit, 2001).

\section{The social justice approach}

The social justice approach is based on the principle of fairness and equality (Weiss, 1998), with the belief that each person must have an equal opportunity in life to strive for meaning and happiness (Boshoff \& Kotzé, 2011; Stead, Worrel \& Stead, 2013). An action or decision is right or wrong, acceptable or unacceptable, depending on whether it results in a fair and equal division of opportunity for all, regardless of irrelevant factors such as race, religion, gender, and age (Solomon, 1994; Boshoff, 2009).
Therefore, the following factors, among others, must be taken into account when the justice principle is applied from an organisational perspective to determine whether individuals received their 'legitimate share' in terms of equality (each individual is the same); merits (the individual's actual contribution); diligence (the amount of work completed, irrespective of the contribution); ability (diligence and results are weighed up against one another to determine what the person can actually do); moral virtue (to set an example or to be a 'good person,' whether it has any effect on results or not); responsibility (willingness to take the blame or to make critical decisions); need (that which a person needs to be able to live comfortably and to be as productive as possible); contractual obligations (previous contracts concluded and promises made must be fulfilled, irrespective of the merits of the matter); and reward for risks taken (compensation for risks taken in order to support a good cause) (Boshoff, 2009; Solomon, 1994). Therefore, in order to determine the acceptability of an action or decision, the justice approach includes certain aspects of the rulebound, the consequentialistic, and the virtuebased approaches.

\section{Relativism}

Ethical relativism is based on the premise that no universal moral principles or objective moral truths or standards exist. The acceptability or unacceptability of any action or decision is not absolute or unchanging, but relative to the individual's own personal preferences (ethical subjectivism), or to the beliefs and values of the culture to which the individual belongs (cultural relativism) (Pojman, 2000; Rae, 1995; Rossouw \& Van Vuuren, 2004; Weiss, 1998). Ethical subjectivists are of the view that individuals establish their own moral standards for the judgment of their actions (Weiss, 1998; Rossouw \& Van Vuuren, 2004), and that ethical behaviour and decisions are therefore based on their own subjective values (Rossouw \& Van Vuuren, 2004; Weiss, 1998). According 
to ethical subjectivists, each person's ethical judgments are only valid for that specific individual, and are not applicable to other individuals, as the values upon which other people base their ethical judgments may differ (Rossouw \& Van Vuuren, 2004). In contrast to ethical subjectivists, cultural relativists are of the opinion that what is ethically correct in one culture may be unacceptable in another. Moral standards may vary between cultures, as a result of each culture's own customs, practices, convictions, and value structures (Weiss, 1998; Boshoff, 2009), which means that there are no universally valid moral principles that apply to all people regardless of their cultural context (Pojman, 2000).

In the development of the WCQ, items for the questionnaire were constructed in a way that attempted to include all six approaches underlying ethical decision making. The first version of the WCQ consisted of 210 items: 95 items from the rule-bound approach, 34 items from the consequentialistic approach, 17 items from the rule-bound consequentialistic approach, 20 items from relativism, 24 items from the virtue approach, and 20 items from the social justice approach.

These items do not focus only on individuals' opinions regarding ethical issues, but also on patterns of behaviour. Hypothetical questions, behavioural questions, as well as situational questions were included in the questionnaire. The following are examples of questions relating to the different approaches included in the questionnaire (WCQ):

Rule-bound approach: To me, business is a game without rules and I have the right to join a strike that is not protected by the Law on Labour Relations;

Consequentialistic approach: Only information that will enhance sales of a product should be included in an advertisement and I consider only the consequences of an action to determine whether it is acceptable, regardless of whether or not a regulation prohibits the action;
Rule-bound consequentialistic approach: I have violated an organisational regulation, as following this rule in that specific situation would have had negative consequences for innocent parties;

Relativism: If punctuality is not an important moral value within my culture, management does not have the right to reprimand me if I am late for meetings and Although there are certain organisational rules that apply to everyone within the organisation, I would obey only those that I feel are applicable to me;

Virtue approach: Loyalty to the organisation is an important quality of a good leader and In my organisation, I am known as someone with integrity;

Social justice approach: It is unethical when someone is paid less on the basis of his/her race for the same work as a person of another race and An organisation has the right to refuse to appoint someone on the grounds of his/her religious convictions.

Both short questions and scenarios (descriptions of an event or situation where an individual is required to make a decision) were used to measure the individual's ethical decisionmaking approach. During the wording of the questions/scenarios, specific attention was paid to formulation errors such as double-barrelled questions, leading questions, emotionally loaded questions, and questions that may lead to socially desirable answers (Bless, HigsonSmith \& Sithole, 2013). In addition, complex and clumsy wording of items was avoided, and the questions/scenarios were stated in a clear, non-ambiguous manner, in order to avoid different interpretations of the questions (Bless et al., 2013). Respondents indicated on a fivepoint Likert scale whether their opinion of a particular statement was: 1 (Do not agree at all), 2 (Sometimes agree), 3 (Often agree), 4 (Often true of me), or 5 (Always agree). The selected items were then presented to a panel of specialists for assessment and evaluation. Although all the items stayed intact after the evaluation, some 
items were rewritten, as the panel was of the opinion that the wording was still too complex. Furthermore, the feedback from the panel indicated that the construct of ethics, as well as the approaches regarding ethical decision making, were well covered. Therefore, the questionnaire was shown to have the necessary content- and face validity.

A discussion of the research design to support the aim of determining the psychometric properties of the WCQ follows.

\section{RESEARCH DESIGN}

\section{Research approach}

In order to achieve the aim of the study and to execute the research, the current study employed a cross-sectional design with a survey data-collection technique.

\section{Research participants}

The WCQ was applied to a sample of 524 participants from different strata within the private and public sectors, using non-probability sampling and, specifically, convenience sampling. This technique was used because only those employees willing to participate in the study were included in the sample. With regard to the biographical information of the respondents, the majority were male (58\%), while $41 \%$ were female. One per cent $(1 \%)$ of the respondents did not indicate their gender. Regarding age, the majority of respondents (71\%) were 40 years or younger, of which $35 \%$ fell in the age category of 20 to 30 years, and a further $36 \%$ in the age category of 31 to 40 years. The minority of respondents $(2 \%)$ were older than 60 years, while $26 \%$ fell in the age category of 41 to 60 years. One per cent (1\%) of the respondents did not indicate their age. Regarding the marital status of the respondents, the majority of respondents (54\%) were married, while $38 \%$ were single. The minority of respondents (7\%) were divorced, with a further $1 \%$ not indicating their marital status.
Regarding tenure, the majority of respondents (59\%) fell in the tenure category of 5 years or more, of which $18 \%$ fell in the tenure category of 6 to 10 years, $13 \%$ in the tenure category of 11 to 15 years, $13 \%$ in the tenure category of 16 to 20 years, and another $13 \%$ in the tenure category of 21 to 30 years. The minority of respondents $(2 \%)$ fell in the tenure category of more than 30 years, while $38 \%$ fell in the tenure category of 5 years or less. Three per cent (3\%) of the respondents did not indicate the length of their service. With regard to the respondents' qualifications, the majority of respondents (92\%) had a qualification of Grade 12 or higher, of which $35 \%$ had only a Grade 12 qualification, $36 \%$ fell in the qualification category of Grade $12+1-3$ years tertiary education, and $21 \%$ fell in the qualification category of more than Grade $12+3$ years tertiary education. The minority of the respondents $(6 \%)$ had Grade 11 or less, while $2 \%$ did not indicate their highest academic qualification.

The statistical analyses employed to test the reliability and validity of the six ethical decisionmaking approaches follows.

\section{Statistical analyses}

To determine the most appropriate structure for the WCQ, both exploratory factor analysis (EFA) and confirmatory factor analysis (CFA) were used (Byrne, 2005). EFA was used to determine which items had significant factor loadings (0.3 and above) (Hair, Black, Babin, Anderson \& Tatham, 2006). For example, 34 items were originally written to operationalise the consequentialistic approach. These 34 items were subjected to an EFA, assuming that these items only measured a single construct (e.g., consequentialism). Only items with significant factor loadings on this unidimensional structure for consequentialism were retained. The same process was applied to the remaining five approaches. When EFA is used for scale development (i.e. questionnaire design), the process requires that the developers use both qualitative and quantitative judgment to 
interpret the results (Worthington \& Whittaker, 2006). For example, using a qualitative stance, the developers can consult relevant ethical theories to determine whether the items are theoretically relevant to the construct. In addition, the EFA results were also judged on the basis of the Kaiser-Meyer-Olkin measure of sampling adequacy (KMO), as well as Bartlett's test of sphericity. For the obtained factor solution to be interpretable, the value associated with the KMO statistic should be 0.6 and above, while a significant result $(\mathrm{p} \leq 0.05)$ is required for Bartlett's test of sphericity (Field, 2005). In the present study, those items that were retained were used to determine the reliability associated with that specific approach. Cronbach's alpha was used to estimate the reliability. Values of 0.6 and above were deemed indicative of acceptable reliability (Hair et al., 2006). As stated by Worthington and Whittaker (2006), "using EFA procedures requires researchers to use inductive reasoning, while patiently and subtly adjusting and readjusting their approach to produce the most meaningful results."

To test the theory that the WCQ provides an accurate measure of the six approaches, CFA was used. The data were treated as continuous. Through analysing the covariance matrix, the data were assessed for normality (Jackson, Gillaspy \& Purc-Stephenson, 2009). Mardia's coefficient was used to determine whether the data violated the assumption of normality (Byrne, 2005). The results suggested that the data deviated from normality in terms of skewness and kurtosis. Bootstrapping, data transformation, and item parcelling may be used to remedy non-normality. Outliers can also be deleted. However, these approaches are not recommended (Brown, 2006). Trimming or changing the data to achieve multivariate normality may not always reflect the true nature of the empirical data (Hair et al., 2006; Field, Miles \& Field, 2012). A more appropriate approach is to use the robust maximum likelihood method of estimation when analysing non-normal data for the purposes of CFA (Brown, 2006).
To deal with model complexity (in terms of the number of items per latent variable), item parcelling was employed. Item parcels were used to evaluate model fit for both the rulebound and the consequentialistic approaches. Due to the fact that the WCQ consists of 140 items, parcelling was again used to evaluate model fit. The purpose of item parcels is to act as indicators of the same latent construct. However, before items can be used in the creation of parcels, the unidimensionality of the items must be determined (Bandalos, 2002; Hagtvet \& Nasser, 2004). In keeping with acceptable practice (Little, Cunningham, Shahar \& Widaman, 2002:166), the factor loadings identified through the EFA were used to anchor the various parcels. Thus, parcels would contain both high and low factor loadings.

All the analyses related to the CFA were conducted using EQS 6.1 (Bentler, 2006). Several fit indices were used, including the SatorraBentler Scaled Chi-square, Root Mean Square Error of Approximation (RMSEA), Standardised Root-Mean Square Residual (SRMR), and the Comparative Fit Index (CFI). Values close to 0.95 for CFI are considered indicative of good model fit. It is suggested that values close to 0.06 are indicative of acceptable fit for RMSEA, while values smaller than 0.08 are acceptable for SRMR (Hu \& Bentler, 1999). In addition, Akaike's Information Criterion (AIC) is used in the comparison of competing measurement models, with smaller values representing a better fit of the proposed model (Byrne, 2005).

In summary, the current study employed best practice with regard to scale development research (Worthington \& Whittaker, 2006) by using both EFA and CFA to determine the most appropriate factors structure for the WCQ and its sub-dimensions. In addition, the developers subjected the items of the questionnaire to subject matter experts, to obtain their opinions and judgments regarding the content of the WCQ. 


\section{RESULTS}

Table 1 provides a summary of the EFA results for each of the six decision-making approaches.

TABLE 1: SUMMARY OF EXPLORATORY FACTOR ANALYSIS RESULTS

\begin{tabular}{|c|c|c|c|c|c|c|c|}
\hline \multirow{2}{*}{$\begin{array}{l}\text { Dimension/ } \\
\text { Approach }\end{array}$} & \multicolumn{3}{|c|}{ Before factor analysis } & \multicolumn{4}{|c|}{ After factor analysis } \\
\hline & $\begin{array}{c}\text { Number of } \\
\text { items }\end{array}$ & KMO & $\begin{array}{c}\text { Bartlett's } \\
\text { test }\end{array}$ & $\begin{array}{c}\text { Number of } \\
\text { items }\end{array}$ & KMO & $\begin{array}{c}\text { Bartlett's } \\
\text { test }\end{array}$ & Alpha \\
\hline Rule-bound approach & 95 & 0.907 & 0.000 & 61 & 0.943 & 0.000 & 0.951 \\
\hline $\begin{array}{l}\text { Consequentialistic } \\
\text { approach }\end{array}$ & 34 & 0.865 & 0.000 & 29 & 0.902 & 0.000 & 0.891 \\
\hline $\begin{array}{l}\text { Rule-bound } \\
\text { consequentialistic } \\
\text { approach }\end{array}$ & 17 & 0.829 & 0.000 & 10 & 0.843 & 0.000 & 0.778 \\
\hline Relativism & 20 & 0.774 & 0.000 & 11 & 0.801 & 0.000 & 0.763 \\
\hline Virtue approach & 24 & 0.865 & 0.000 & 12 & 0.915 & 0.000 & 0.865 \\
\hline $\begin{array}{l}\text { Social justice } \\
\text { approach }\end{array}$ & 20 & 0.886 & 0.000 & 17 & 0.900 & 0.000 & 0.840 \\
\hline
\end{tabular}

From Table 1, it is evident that all the latent constructs have acceptable levels of reliability, ranging from 0.763 to 0.951 , after the removal of items with non-significant loadings.
The CFA results for each of the six decisionmaking approaches are presented in Table 2.

TABLE 2: CONFIRMATORY FACTOR ANALYSIS RESUlTS: DIMENSIONS/APPROACH

\begin{tabular}{l|c|c|c|c|c|c}
\hline $\begin{array}{c}\text { Fit } \\
\text { Index }\end{array}$ & $\begin{array}{c}\text { Rule-bound } \\
\text { approach } \\
\text { (parcels) }\end{array}$ & $\begin{array}{c}\text { Consequentialistic } \\
\text { approach } \\
\text { (parcels) }\end{array}$ & $\begin{array}{c}\text { Rule-bound } \\
\text { consequentialistic } \\
\text { approach }\end{array}$ & Relativism & $\begin{array}{c}\text { Virtue } \\
\text { approach }\end{array}$ & $\begin{array}{c}\text { Social justice } \\
\text { approach }\end{array}$ \\
\hline S-B X & 127.9580 & 86.8875 & 122.1216 & 244.5650 & 147.2102 & 351.7335 \\
\hline $\mathrm{df}$ & 54 & 27 & 35 & 44 & 54 & 119 \\
\hline $\mathrm{CFI}$ & 0.975 & 0.965 & 0.900 & 0.800 & 0.931 & 0.860 \\
\hline RMSEA & 0.051 & 0.065 & 0.069 & 0.093 & 0.057 & 0.061 \\
& $(0.040 ; 0.063)$ & $(0.050 ; 0.080)$ & $(0.056 ; 0.082)$ & $(0.082 ; 0.105)$ & $(0.046 ; 0.068)$ & $(0.054 ; 0.068)$ \\
\hline SRMR & 0.025 & 0.037 & 0.057 & 0.077 & 0.046 & 0.066 \\
\hline
\end{tabular}

The goodness-of-fit statistics for all six approaches are reported in Table 2. It is noteworthy that the majority of the six approaches have acceptable levels of fit (e.g., CFI, RMSEA, and SRMR). However, the relativism, social justice, and rule-bound consequentialistic approaches have room for some improvement in terms of overall fit, in terms of the CFI.

Goodness-of-fit statistics for each of the three competing conceptualisations of the WCQ are provided in Table 3.

TABLE 3: SUMMARY OF CONFIRMATORY FACTOR ANALYSIS RESULTS

\begin{tabular}{l|c|c|c}
\hline Fit Index & $\begin{array}{c}\text { Six-factor } \\
\text { structure }\end{array}$ & $\begin{array}{c}\text { Three-factor } \\
\text { structure }\end{array}$ & $\begin{array}{c}\text { Unidimensional factor } \\
\text { structure }\end{array}$ \\
\hline $\mathrm{S}-\mathrm{B} \mathrm{X^{2 }}$ & 965.6347 & 491.5225 & 1716.7177 \\
\hline $\mathrm{df}$ & 390 & 186 & 404 \\
\hline $\mathrm{CFI}$ & 0.937 & 0.950 & 0.855 \\
\hline RMSEA & 0.051 & 0.056 & 0.079 \\
\hline SRMR & $(0.049 ; 0.057)$ & $(0.050 ; 0.062)$ & $(0.075 ; 0.083)$ \\
\hline AIC & 0.051 & 0.049 & 0.070 \\
\hline
\end{tabular}


In order to determine the most accurate representation of the WCQ, three competing measurement models were evaluated: the original six-factor structure, a unidimensional structure, and a three-factor structure. The latter was informed by the weaker fit, as evidenced by the following three approaches: the rule-bound consequentialistic approach, relativism, and the social justice approach (see Table 2).
It is clear that, although the original six-factor structure of the WCQ shows evidence of acceptable fit, it is outperformed by the threefactor structure, specifically when looking at AIC. The evaluation of a measurement model that assumes the WCQ measures a single construct is, however, not supported.

The correlations among the ethical decisionmaking approaches are provided in Tables 4 and 5.

TABles 4: Phi matrix (ORIginal structure)

\begin{tabular}{|c|c|c|c|c|c|c|}
\hline Dimension/approach & 1 & 2 & 3 & 4 & 5 & 6 \\
\hline 1. Rule-bound approach & 1 & & & & & \\
\hline 2. Consequentialistic approach & 0.47 & 1 & & & & \\
\hline 3. Rule-bound consequentialistic approach & 0.39 & 0.36 & 1 & & & \\
\hline 4. Relativism & 0.40 & 0.34 & 0.28 & 1 & & \\
\hline 5. Virtue approach & 0.44 & 0.34 & 0.30 & 0.29 & 1 & \\
\hline 6. Social justice approach & 0.60 & 0.48 & 0.42 & 0.41 & 0.53 & 1 \\
\hline
\end{tabular}

TABle 5: Phi matrix (Three-factor Structure)

\begin{tabular}{l|c|c|c}
\hline \multicolumn{1}{c|}{ Dimension/approach } & $\mathbf{1}$ & $\mathbf{2}$ & $\mathbf{3}$ \\
\hline 1. Rule-bound approach & $\mathbf{1}$ & 1 & \\
\hline 2. Consequentialistic approach & 0.47 & 0.34 & 1 \\
\hline 3. Virtue approach & 0.44 & & \\
\hline
\end{tabular}

If the original structure of the WCQ is retained, it is noteworthy that the majority of approaches have moderate correlations, ranging between 0.29 and 0.60 (see Table 4). Of interest is that the virtue approach seems to exhibit the lowest correlations with the other approaches. A similar pattern seems to emerge when looking at the correlations in Table 5.

\section{DISCUSSION OF RESULTS}

The items operationalising the rule-bound approach (consisting of 61 items) were highly reliable $(\alpha=0.95)$. In addition, the items measuring both the consequentialistic approach (29 items; $\alpha=0.89$ ) and the virtue approach (12 items; $\alpha=0.87$ ) also had high reliabilities. The measurement models representing the first two ethical decision-making approaches exhibited excellent fit to the data, while the virtue approach exhibited a good fit. It can therefore be concluded that the WCQ provides valid and reliable measures of the rulebound, the consequentialistic, and the virtue approaches to ethical decision making.

From previous research on ethical decisionmaking approaches (e.g., Chryssides \& Kaler, 2005; Desjardins, 2006; Esterhuyse, 1991; Garofalo, 2003; Gibson, 2007; Kline, 2005; Malloy \& Zakus, 1995; Pojman, 2000; Rae, 1995; Rossouw et al., 2006; Rossouw \& Van Vuuren, 2004; Solomon, 1994; Trevino \& Nelson, 2007; Weiss, 1998), it appears that these three approaches (rule-bound, consequentialistic, and virtue) are the most prominent. Malan and Smit (2001), as well as Garofalo (2003), also identified certain shared values within a labour context, which are found in most organisations, such as adaptability, transparency, taking others into account, openness, respect for all, service, incorruptibility, integrity, fairness, effectiveness, impartiality, loyalty, honesty, 
quality, competence, accountability, striving for excellence, diligence, and caring for others. When focusing on these shared values, the importance of these three main decision-making approaches is clearly evident. These values require employees to focus, not only on the consequences of their actions, but also on the rules and virtues that guide ethical behaviour within the work context.

With regard to the other three decision-making approaches (rule-bound consequentialistic approach, social justice approach, and relativism), the items that measure the rulebound consequentialistic approach (10 items) exhibited an acceptable level of reliability $(\alpha=0.95)$. However, the goodness-of-fit statistics (e.g., CFI) may indicate room for some improvement. The weaker fit may be attributed to respondents having answered these questions in such a manner that they did not focus on both the rule, which guides a specific action, and the consequences of the action. Therefore, the possibility exists that respondents only focused on either the rule or the consequences, without weighing them against each other. The weaker fit may also be attributed to the possibility that the rule-bound consequentialistic approach might be linked to higher levels of moral reasoning, associated with Kohlberg's final stage of moral development (Kohlberg, 1969; Louw \& Edwards, 2005). According to Kohlberg (1996; Louw \& Edwards, 2005), only a small percentage of individuals reach this stage.

With the regard to the social justice approach (consisting of 17 items), the items exhibited an acceptable reliability $(\alpha=0.84)$. However, the unidimensional conceptualisation of this construct seems to leave room for some improvement, as evident by the weaker fit in terms of CFI and, to a lesser extent, RMSEA. The weaker fit may also be attributed to a possible overlap between this approach and the rule-bound, the consequentialistic, and the virtue approaches. According to Esterhuyse (1991; Boshoff \& Kotzé, 2011), the social justice approach is based on the stance that each person must have an equal opportunity in life to strive for meaning and happiness (which forms part of utilitarianism, one of the dimensions of the consequentialistic approach). Weiss (1998; Boshoff, 2009) added that this approach is based on the principle of fairness and equality - both virtues. Furthermore, the philosopher John Rawls (1971; Boshoff \& Kotzé, 2011; Weiss, 1998) established two sets of rules (rule-bound approach) upon which the justice principle is based: firstly, all people must receive equal treatment and, secondly, all people must, on the grounds of their position and status, have equal access to those opportunities established by society. From the aforementioned discussion of the social justice approach, it is apparent that this approach includes certain aspects of the rule-bound, the consequentialistic, and the virtue-based approaches in determining the acceptability of an action or decision.

The 11 items used to measure relativism also exhibited acceptable levels of reliability $(\alpha=0.76)$. Yet, the unidimensional conceptualisation of this construct, as evident by the weaker fit in terms of CFI, and to a lesser extent RMSEA, seems to leave room for some improvement. It should be noted that this weaker fit may be attributable to fact that the questions included in the WCQ focus on both subjectivism (which states that the acceptability of a decision is relative to individual personal preferences) and cultural relativism (according to which the acceptability of a decision is relative to the culture to which the individual belongs). Therefore, it may be considered to regard these two sub-dimensions as two separate approaches, instead of sub-dimensions of the same approach.

Note, however, that although the fit statistics indicated a weaker fit for these three approaches (rule-bound consequentialistic approach, social justice approach, and relativism), their reliabilities (refer to Table 1) appear to be satisfactory. All three these constructs are welldefined in terms of the items - as highlighted by their reliabilities, as well as the opinion of 
expert judges who rated these items. Therefore, these approaches can indeed still be included in the WQC.

Despite the fact that the WCQ seems to have acceptable psychometric properties, it is also necessary to compare it to other ethical decision-making instruments (as discussed previously) that also measure ethical decisionmaking approaches. When comparing the WCQ to the EPQ (Forsyth, n.d.), the findings of the current study seem promising. Davis et al. (2001) investigated the most appropriate factor structure associated with the EPQ. The latter instrument consists of 10 items measuring idealism, with another 10 items measuring relativism. Davis et al. (2001) tested three different models: a unidimensional structure, a two-dimensional structure consisting of idealism and relativism, and, finally, a threedimensional structure (idealism, relativism, and veracity). Unfortunately, these authors focused mainly on the CFI (ranging from 0.43 to 0.91 ) as a measure of fit. It is clear that both the six-dimensional and the three-dimensional conceptualisation of the WCQ have a much better fit than the EPQ.

Another well-known instrument often used in ethics research is the Multidimensional Ethics Scale (MES) (Kujala et al., 2011). Two versions of the MES were developed. The 30-item version (MES-30) consists of five dimensions: (a) deontology, (b) utilitarianism, (c) relativism, (d) egoism, and (e) justice. A shorter version, consisting of just eight items (MES-8), measures three distinct dimensions: (a) broad-based moral equity, (b) relativism, and (c) contractualism. McMahon and Harvey (2007) investigated the psychometric properties associated with both these versions. These authors found support for the three-dimensional structure of the MES-8 (McMahon \& Harvey, 2007), as described earlier. Unfortunately, a meaningful comparison can only be made using the CFI value. The MES-8 (three dimensions) had a CFI of 0.97. Both the three-dimensional $(\mathrm{CFI}=0.94)$ and the sixdimensional $(\mathrm{CFI}=0.95)$ structures of the WCQ had comparable values.
When comparing the WCQ to the ATBEQ, the psychometric properties of the WCQ seem to be superior to those of the ATBEQ. No psychometric properties were communicated by the developers of the ATBEQ (Preble \& Reichel, 1988). In a South African study, the ATBEQ produced a Cronbach alpha of 0.69 across all 30 items. The factor analysis results of the ATBEQ were less stable, with up to 11 factors being suggested (Price \& Van der Walt, 2013).

\section{CONCLUSIONS AND RECOMMENDATIONS}

Regarding the six ethical decision-making approaches identified from the literature, the items that measured the rule-bound approach, the consequentialistic approach, and the virtue approach showed high reliabilities. The measurement models representing the rulebound approach, as well as the consequentialistic approach, exhibited excellent fit to the data, while the virtue approach exhibited a good fit. It can therefore be concluded that the WCQ provides valid and reliable measures of these three ethical decision-making approaches.

With regard to the other three decision-making approaches (rule-bound consequentialistic approach, social justice approach, and relativism), the items that measured these approaches exhibited an acceptable level of reliability. Although the fit statistics indicated a weaker fit for these three approaches, all three these constructs (approaches) are welldefined in terms of the items, as highlighted by their reliabilities, as well as the opinion of expert judges who rated these items. Therefore, these approaches can indeed still be included in the WQC.

Given the fact that the unidimensional conceptualisation of the WCQ did not receive any support, it is evident that the WCQ should be treated as a multi-dimensional construct that measures several well-defined ethical decision-making approaches. Support for the latter conceptualisation was also obtained from 
the moderate correlations among the various decision-making approaches.

The following recommendations are made for future research and for practical application of this study. Firstly, it is recommended that future studies focus on determining whether a possible overlap exists between the social justice approach and the rule-bound, consequentialistic, and virtue approaches. After said studies have been conducted, the questionnaire should be adapted accordingly, if necessary. Secondly, it is recommended that a measurement model/framework, based on possible sub-approaches/-dimensions relating to each of the main approaches regarding ethical decision making, be developed and statistically evaluated. This will address the possible overlap between some of the main approaches, as indicated in this article. Thirdly, it is suggested that the psychometric properties of the WCQ be adapted and tested based on the above-mentioned measurement model/ framework, in order to identify, not only the main ethical decision-making approaches, but also the sub-approaches associated with each main ethical decision-making approach followed by employees. Fourthly, it is suggested that the Rasch model (Fox \& Bond, 2007) be applied to evaluate the psychometric properties associated with the WCQ. The Rasch model will make it possible to determine the difficulty levels associated with each of the decisionmaking approaches. For example, is it more difficult for an individual to exhibit behaviours associated with the rule-bound approach than with the virtue approach? These results may then assist with the development of possible interventions.

Fifthly, it is recommended that interventions be developed and implemented in order to improve ethical behaviour in organisations. Should organisations wish to remain part of the highly competitive global market, a renewed focus on ethical behaviour will be imperative. In this regard, the WCQ provides an important aid to organisations in determining the manner in which ethical problems are approached by current and potential employees. With this knowledge, the necessary interventions can be implemented in a proactive manner where necessary. Finally, the WCQ can also be a useful aid during the recruitment of employees.

The value of this study stems from the fact that it addresses the need for a reliable and valid work ethics questionnaire that provides an indication of the approach followed by employees during ethical decision making.

\section{REFERENCES}

Aristotle. 1972. The Nicomachean ethics of Aristotle. Translated by D. Ross. London: Oxford University Press.

Aristotle. 1977. The ethics of Aristotle: The Nicomachean ethics. Translated by J. A. K. Thomson, revised by H. Tredennick. England: Penguin Books.

Ashley, P., Powers, C. \& Schunter, M. 2002. From privacy promises to privacy management. Proceedings of the 2002 Workshop on New Security Paradigms, Virginia Beach, Virginia.

Bandalos, D. L. 2002. The effects of item parceling on goodness-of-fit and parameter estimate bias in structural equation modeling. Structural Equation Modeling, 9:78-102.

Bentler, P. M. 2006. EQS 6: Structural equations program manual. California: Multivariate Software.

Bless, C., Higson-Smith, C. \& Sithole, S. L. 2013. Fundamentals of social research methods: An African perspective. 5th Edition. Cape Town: Juta Education (Pty) Ltd.

Boshoff, E. 2009. Die ontwikkeling van 'n werksetiekvraelys gebaseer op 'n holistiese filosofiese model van etiese besluitneming. Unpublished doctoral thesis. Bloemfontein: University of the Free State.

Boshoff, E. \& Kotzé, M. 2011. The conceptualization and measurement of philosophical approaches that influence ethical decision-making in the work context: Part 1. African fournal of Business Ethics, 5(1):36-49. 
Brown, T. A. 2006. Confirmatory factor analysis for applied research. New York, NY: Guilford Press.

Byrne, B. M. 2005. Factor analytic models: Viewing the structure of an assessment instrument from three perspectives. Journal of Personality Assessment, 85:17-32.

Chryssides, G. D. \& Kaler, J. H. 2005. An introduction to business ethics. London: Thomson Learning.

Davis, M. A., Andersen, M. G. \& Curtis, M. B. 2001. Measuring ethical ideology in business ethics: A critical analysis of the Ethics Position Questionnaire. Fournal of Business Ethics, 32:35-53.

Desjardins, J. 2006. An introduction to business ethics. 2nd Edition. Boston: McGraw-Hill.

Desjardins, J. R. \& McCall, J. 1996. Contemporary issues in business ethics. 3rd Edition. Belmont: Wadsworth Publishing Company.

Esterhuyse, W. 1991. Sake-etiek in die praktyk. Pretoria: J. L. van Schaik (Edms.) Bpk.

Field, A. 2005. Discovering statistics using SPSS. 2nd Edition. London: SAGE Publications Ltd.

Field, A., Miles, J. \& Field, Z. 2012. Discovering statistics using $R$. Thousand Oaks, California: Sage Publications.

Forsyth, D. R. (n.d.) Studying our social world. [Online] Available: http://donforsyth. wordpress.com/ethics/ethics-positionquestionnaire [Accessed 1 August 2013].

Fox, C. M. \& Bond, T. G. 2007. Applying the Rasch model: Fundamental measurement in the human sciences. 2nd Edition. Mahwah, N.J.: Erlbaum.

Garofalo, C. 2003. Toward a global ethic: Perspectives on values, training and moral agency. International fournal of Public Sector Management, 16(7):490-501.

Gibson, K. 2007. Ethics and business: An introduction. New York: Cambridge University Press.

Gordon, K. \& Miyake, M. 2001. Business approaches to combating bribery: A study of codes of conduct. Fournal of Business Ethics, 34:161-173.
Gross-Schaefer, A., Trigilio, J., Negus, J. \& Ro, C. S. 2000. Ethics education in the workplace: An effective tool to combat employee theft. Fournal of Business Ethics, 26:89-100.

Hagtvet. K. A. \& Nasser, F. M. 2004. How well do item parcels represent conceptually defined latent constructs? A two-facet approach. Structural Equation Modeling, 11(2):168-193.

Hair, J. F., Black, W. C., Babin, B. J. Anderson, R. E. \& Tatham, R. L. 2006. Multivariate data analysis. 6th Edition. Upper Saddle River, New Jersey: Prentice Hall.

Hu, L. \& Bentler, P. M. 1999. Cut-off criteria for fit indexes in covariance structure analysis: Conventional criteria versus new alternatives. Structural Equation Modeling, 6(1):1-55.

Jackson, D. L., Gillaspy, J. A. \& Purc-Stephenson, R. 2009. Reporting practices in confirmatory factor analysis: An overview and some recommendations. Psychological Methods, 14(1):6-23.

James, H. S. 2002. When is a bribe a bribe? Teaching a workable definition of bribery. Teaching Business Ethics, 6(2):199-217.

Kline, J. M. 2005. Ethics for international business: Decision-making in a global political economy. London: Routledge.

Kohlberg, L. 1969. Stage and sequence: The cognitive-developmental approach to socialization. In D. A. Goslin (Ed.), Handbook of socialization theory and research. Chicago: Rand McNally College Publishing Company.

Kujala, J., Lamsa, A. \& Penttila, K. 2011. Managers' moral decision-making patterns over time: A multidimensional approach. Journal of Business Ethics, 100:191-207.

Kujala, J. \& Pietiläinen, T. 2007. Developing moral principles and scenarios in the light of diversity: An extension to the Multidimensional Ethics Scale. Journal of Business Ethics, 70(2):141-150. 
Little, T. D., Cunningham, W. A., Shahar, G. \& Widaman, K. F. 2002. To parcel or not to parcel: Exploring the question, weighing the merits. Structural Equation Modelling, 9:151-173.

Louw, D. A. \& Edwards, D. J. A. 2005. Psychology: An introduction for students in Southern Africa. 2nd Edition. Sandton: Heinemann Higher \& Further Education (Pty) Ltd.

MacNab, Y. C., Malloy, D. C., Hadjistavropoulos, T., Sevigny, P.R., McCarthy, E. F., Murakami, M., Paholpak, S., Natarajan, S. \& Liu, P. L. 2011. Idealism and relativism across cultures: A cross-cultural examination of physicians' responses on the Ethics Position Questionnaire (EPQ). fournal of Cross-Cultural Psychology, 42(7):1272-1278.

Malan, F. \& Smit, B. 2001. Ethics and leadership in business and politics. Lansdowne: Juta.

Malloy, D. C. \& Zakus, D. H. 1995. Ethical decision-making in sport administration: A theoretical inquiry into substance and form. Fournal of Sport Management, 9:36-58

McCall, J. J. 2006. Deceptive advertising. In F. Allhoff \& A. Vaidya (Eds.), Business ethics (Volume III). London: SAGE Publications.

McMahon, J. M. \& Harvey, R. J. 2007. Psychometric properties of the Reidenbach-Robin Multidimensional Ethics Scale. Fournal of Business Ethics, 72:27-39.

Moore, R. S. \& Radloff, S. E. 1996. Attitudes towards business ethics held by South African students. Fournal of Business Ethics, 15:863-869.

Pojman, L. P. 2000. Life and death: Grappling with the moral dilemmas of our time. 2nd Edition. Belmont, CA: Wadsworth Publishing Company.

Preble, J. F. \& Reichel, A. 1988. Attitudes towards business ethics of future managers in the U.S. and Israel. fournal of Business Ethics, 7(12):941-949.

Price, G. \& Van der Walt, A. J. 2013. Changes in attitudes towards business ethics. Fournal of Business Ethics, 113:429-440.
Rae, S. B. 1995. Moral choices: An introduction to ethics. Grand Rapids, Michigan: Zondervan.

Rawls, J. 1971. A theory of justice. Cambridge, Massachusetts: Harvard University Press.

Rossouw, D., Prozesky, M., Van Heerden, B. \& Van Zyl, M. 2006. Ethics for accountants and auditors. Cape Town: Oxford University Press.

Rossouw, D. \& Van Vuuren, L. 2004. Business ethics. 3rd Edition. Cape Town: Oxford University Press Southern Africa.

Sims, R. L. \& Gegez, A. E. 2004. Attitudes towards business ethics: A five nation comparative study. Fournal of Business Ethics, 50:253-265.

Small, M. W. 1992. Attitudes towards business ethics held by Western Australian students: A comparative study. Journal of Business Ethics, 11:745-752.

Solomon, R. C. 1994. Above the bottom line: An introduction to business ethics. 2nd Edition. Orlando: Harcourt Brace College Publishers.

Stead, W. E., Worrel, D. L. \& Stead, J. G. 2013. An integrative model for understanding and managing ethical behaviour in organizations. In A. C. Michalos \& D. C. Poff (Eds.), fournal of Business Ethics: Celebrating the first thirty years of publication. Oxford: ButterworthHeinemann Ltd.

Swanepoel, B., Erasmus, B., Van Wyk, M. \& Schenk, H. 2003. South African human resource development: theory and practice. 3rd Edition. Lansdowne: Juta.

Trevino, L. K. \& Nelson, K. A. 2007. Managing business ethics: Straight talk about how to do it right. 4th Edition. USA: John Wiley \& Sons, Inc.

Weiss, J. W. 1998. Business ethics: A stakeholder and issues management approach. 2nd Edition. Orlando: Harcourt Brace College Publishers.

Worthington, R. L. \& Whittaker, T. A. (2006). Scale development research: A content analysis and recommendations for best practice. The Counseling Psychologist, 34:806-838. 